\title{
Rehabilitation for Ankylosing Spondylitis in the Era of Biologics: Any Room Left for This Treatment?
}

In 1955, Lawrence and Sladden wrote an article on the value of physiotherapy in rheumatic diseases ${ }^{1}$. As an introduction to their article they wrote: "In assessing the value of a method of treatment for rheumatic diseases the problem may be approached from 2 different angles: (1) whether the remedy relieves the pain and (2) whether it hastens recovery or renders

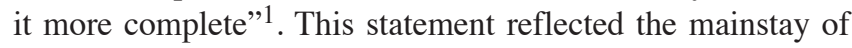
the management of patients with ankylosing spondylitis (AS) for many years. Using a time machine, we can move from the mid-1950s to the third millennium when the ASsessment of SpondyloArthritis International Society (ASAS) proposed evidence based recommendations to guide the physician in the management of $\mathrm{AS}^{2}$. In fact, although the use of anti-tumor necrosis factor- $\alpha$ treatment in AS patients must be considered a revolution in the treatment strategy of AS, the ASAS strengthened support for the approach that optimal management of AS requires a combination of non-pharmacological and pharmacological treatments ${ }^{2}$. Indeed, rehabilitation is still considered one of the main treatment strategies, most of the time showing beneficial effects; and non-pharmacological therapy (including education, exercise, and physiotherapy) was included in the recommendations for AS management by the ASAS working group/EULAR ${ }^{2}$. In the first update of these recommendations, it has been emphasized that regular exercise and patient education are the cornerstone of non-pharmacological treatment of AS and that supervised exercises are more effective than home exercises ${ }^{3}$.

However, even considering the important role of rehabilitation, at least 2 main issues are still being addressed:

(1) What strong evidence exists of the type of physical therapy/rehabilitation that is most effective in AS patients, and what is the duration of the positive effects of this treatment? In other words, how long does the positive effect last?

(2) In the biological era is rehabilitation still worth considering for patients with AS?

To address the first issue we can state that physiotherapy interventions for AS have been shown to be an important part of management of the disease, being useful with a tendency to be more effective when done as a supervised outpatient group ${ }^{4,5,6}$. The most recent reviews on physiotherapy interventions confirmed this treatment strategy, also indicating that exercise performed by patients under supervision was beneficial for spinal mobility when compared to the home exercise regimen, but suggested that further research was essential to delineate which exercise protocols should be recommended in the management of AS patients ${ }^{4}$. Moreover, Nghiem, et $a l^{7}$ and Elyan, et $\mathrm{al}^{8}$ in their reviews on the rehabilitation of AS conclude, on the basis of a few published articles, that exercise should remain a mainstay of AS treatment complementing medical therapy, but that there is a need for a standardized approach to assess its real role.

A few years ago, a Korean group showed that a home-based daily exercise program increased joint mobility and functional capacity, and decreased pain and depression in AS patients ${ }^{9}$. They concluded that home based exercise might be an effective intervention for the disease.

To estimate the duration of positive effects of physiotherapy, again, there are no clear results. In fact, on the basis of previous results, various other studies showed that inpatient intensive rehabilitation is effective in inducing short term improvement in spinal mobility ${ }^{10}$, but doubts remain about sustained improvement after long periods ${ }^{11,12,13}$. Some data showed that patients with AS experienced progressive loss of movement independent of the duration of the disease and of the reported frequency of unsupervised exercise ${ }^{14}$.

We showed the effectiveness of inpatient rehabilitation assessed by ASAS response criteria and this was quite a novelty using a combined index to measure the real role of rehabilitation ${ }^{15}$. Indeed and interestingly, the effectiveness of intensive inpatient rehabilitation declined over time, suggesting that this therapeutic approach, per se, is not effective enough to control the disease. However, to better measure the effectiveness of rehabilitation, it would be advisable to use the ASAS response criteria in rehabilitation settings.

These contradictory results may be due to methodological differences such as patient selection and physiotherapy regimen. All these results showed, clearly, that any rehabilitation program only plays a partial role in the treatment of the disease and fails to completely address the management of AS patients.

To address the second point on the possible role of rehabilitation in the era of biologics, we would consider only a combined approach (biological agents and rehabilitation). The concept of combination treatment has gained some prominence in the last few years and, at present, a few papers showed the synergistic effect of biological agents and rehabilitation. In one study designed by us, etanercept and intensive inpatient rehabilitation was used for the management of active AS, indicating that combination treatment seemed to be more effective than a simple rehabilitation program ${ }^{16}$. A possible explanation for the good results obtained was that the tumor necrosis factor- $\alpha$ (TNF) antagonist, acting on inflammation

Personal non-commercial use only. The Journal of Rheumatology Copyright (c) 2011. All rights reserved. 
and reducing fatigue, improved the effectiveness of a rehabilitation program, resulting in better functional status, better quality of life, and better perception of benefits obtained from the rehabilitation. Similar results were obtained by another study, in which an occupational treatment in combination with biological agents was beneficial, with synergistic effects on pain, function, and disability when compared to the control group treated with simple occupational therapy ${ }^{17}$. Moreover, the study also showed that occupational therapy could be effective when associated with powerful biologic medications, also being a useful way to maintain and improve health status of AS patients when the disease is stable and well controlled with the drugs. Other authors showed that a combination of anti-TNF- $\alpha$ agents and rehabilitation can improve the benefit perceived by the AS patients when doing physiothera$\mathrm{py}^{18}$. Thus, there is a strong body of evidence that rehabilitation can improve the effects of anti-TNF- $\alpha$ agents.

In this issue of The Journal Masiero, et al show results of a randomized study on rehabilitation in AS patients with clinically stabilized disease on anti-TNF- $\alpha$ treatment ${ }^{19}$. The authors showed promising results with an improvement of all outcome measures, including Bath Ankylosing Disease Activity Index and some anthropometric indexes. The possible explanation for these results could be partly related to the concomitant biological treatment and partly to the good level of patients' motivation in following the rehabilitation program. Indeed the study, innovative to some extent, also showed a positive effect of rehabilitation in the outcome measures, which was superior to those obtained from the previous course of biological therapy alone. This, in turn, could support the concept of combination treatment, but this does need more confirmation from other studies, such as multicenter randomized trials measuring outcome by a widely and accepted composite index (i.e., ASAS response criteria). Alternatively, the message could be that rehabilitation per se is the most effective treatment in AS patients.

We are pursuing the concept of a combination treatment as a way of better management of this fascinating and challenging disease $\mathrm{e}^{20}$. Even if the modality of combination is not yet clear, we hypothesize that adding rehabilitation to biological therapy could increase its effectiveness and/or prevent a possible treatment failure.

ENNIO LUBRANO, MD, PhD, Senior Lecturer,

Academic Rheumatology Unit, Department of Health Sciences, University of Molise, Campobasso;

SALVATORE D'ANGELO, mD, Researcher,

Rheumatology Department of Lucania,

San Carlo Hospital of Potenza and

Madonna delle Grazie Hospital of Matera;

Department of Health Sciences,

University of Molise, Campobasso;

ANTONIO SPADARO, MD, Associate Professor,

Dipartimento di Medicina Interna e Specialità Mediche,

UOC di Reumatologia,

"Sapienza" Università di Roma, Rome;
CARLO PALAZZI, MD, Senior Investigator; IGNAZIO OLIVIERI, MD, Head;

Rheumatology Department of Lucania,

San Carlo Hospital of Potenza and

Madonna delle Grazie Hospital of Matera,

Potenza, Italy.

Address correspondence to Dr. Olivieri.

E-mail: ignazioolivieri@tiscalinet.it

\section{REFERENCES}

1. Lawrence JS, Sladden RJ. The value of physiotherapy in rheumatic diseases. I. Palliation. Am Phys Med 1955;2:282-9.

2. Zochling J, van der Heijde D, Burgos Vargas R, Collantes E, Davis JC Jr, Dijkmans B, et al. ASAS/EULAR recommendations for the management of ankylosing spondylitis. Ann Rheum Dis 2006;65:442-52.

3. Braun J, van den Berg R, Baraliakos X, Boehm H, Burgos-Vargas $\mathrm{R}$, Collantes E, et al. First update of the ASAS/EULAR recommendations for the management of ankylosing spondylitis. Ann Rheum Dis 2011;70:896-904.

4. Dagfinrud H, Kvien TK, Hagen KB. Physiotherapy interventions for ankylosing spondylitis. Cochrane Database Syst Rev 2008;CD002822.

5. van der Linden S, van Tubergen A, Hidding A. Physiotherapy in ankylosing spondylitis: what is the evidence? Clin Exp Rheumatol 2002;20 Suppl 28:S60-4.

6. Analay Y, Ozcan E, Karan A, Diracoglu D, Aydin R. The effectiveness of intensive group exercise on patients with ankylosing spondylitis. Clin Rehabil 2003;17:631-6.

7. Nghiem FT, Donohue JP. Rehabilitation in ankylosing spondylitis. Curr Opin Rheumatol 2008;20:203-7.

8. Elyan M, Khan MA. Does physical therapy still have a place in the treatment of ankylosing spondylitis? Curr Opin Rheumatol 2008;20:282-6.

9. Lim HJ, Moon YI, Lee MS. Effects of home-based daily exercise therapy on joint mobility, daily activity, pain, and depression in patients with ankylosing spondylitis. Rheumatol Int 2005;25:225-9.

10. van Tubergen A, Landewe R, van der Heijde D, Hidding A, Wolter $\mathrm{N}$, Asscher M, et al. Combined spa-exercise therapy is effective in patients with ankylosing spondylitis: a randomized controlled trial. Arthritis Rheum 2001;45:430-8.

11. Viitanen JV, Suni J, Kautiainen H, Liimatainen M, Takala H. Effect of physiotherapy on spinal mobility in ankylosing spondylitis. Scand J Rheumatol 1992;21:38-41.

12. Helliwell PS, Abbott CA, Chamberlain MA. A randomised trial of three different physiotherapy regimes in ankylosing spondylitis. Physiotherapy 1996;82:85-90.

13. Kraag G, Stokes B, Groh J, Helewa A, Goldsmith CH. The effects of comprehensive home physiotherapy and supervision on patients with ankylosing spondylitis - an 8-month follow up. J Rheumatol 1994;21:261-3.

14. Lubrano E, Helliwell P. Deterioration in anthropometric measures over six years in patients with ankylosing spondylitis. An initial comparison with disease duration and reported exercise frequency. Physiotherapy 1999;85:138-43.

15. Lubrano E, D’Angelo S, Parsons WJ, Corbi G, Ferrara N, Rengo F, et al. Effectiveness of rehabilitation in active ankylosing spondylitis assessed by the ASAS response criteria. Rheumatology 2007;46:1672-5.

16. Lubrano E, D'Angelo S, Parsons WJ, Serino F, Tanzillo AT, Olivieri I, et al. Effects of a combination treatment of an intensive rehabilitation program and etanercept in patients with ankylosing spondylitis: a pilot study. J Rheumatol 2006;33:2029-34. 
17. Spadaro A, De Luca T, Massimiani MP, Ceccarelli F, Riccieri B, Valesini G. Occupational therapy in ankylosing spondylitis: short-term prospective study in patients treated with anti-TNF-alpha drugs. Joint Bone Spine 2008;75:29-33.

18. Dubey SG, Leeder J, Gaffney K. Physical therapy in anti-TNF treated patients with ankylosing spondylitis. Rheumatology 2008;47:1100-1.

19. Masiero S, Bonaldo L, Pigatto M, Lo Nigro A, Ramonda R, Punzi
L. Rehabilitation treatment in the management of patients with ankylosing spondylitis stabilized with TNF inhibitor therapy. A randomized controlled trial. J Rheumatol 2011 Apr 1 Epub ahead of print.

20. Lubrano E, Spadaro A. From rehabilitation to remission in ankylosing spondylitis. Reumatismo 2009;61:241-3.

J Rheumatol 2011;38:1228-30; doi:10.3899/jrheum.110362 